ARTICLE

Received 23 Oct 2014 | Accepted 30 Mar 2015 | Published 19 May 2015

\title{
Quantifying urban economic resilience through labour force interdependence
}

Shade T Shutters ${ }^{1}$, Rachata Muneepeerakul ${ }^{2}$ and José Lobo ${ }^{3}$

\begin{abstract}
Resilience is increasing rapidly as a framework to understand and manage coupled human-natural systems. Yet the concept of resilience is rarely quantified. Here we quantify system resilience by operationalizing the notion of system tightness. Multiple resilience frameworks recognize the strong relationship between system tightness and resilience, though they differ on the directionality of that relationship. Thus, by measuring the system tightness we ultimately measure urban economic resilience, with the added benefit of empirically determining the directionality of the relationship between tightness and resilience. We then assess how well this measure predicts the response of urban economies to the recent so-called Great Recession. Results show that cities with lower tightness (higher resilience) fared better during the recession with respect to several economic productivity measures. However, in the absence of shocks, those with higher tightness (lower resilience) exhibit superior economic performance. Thus, a tradeoff between efficiency and resilience is nicely reflected in the empirical data. Although this study deals with economic shocks, quantitative metrics based on its methodology may help anticipate a city's response to shocks more generally, such as natural disasters, climate change, social unrest or significant policy shifts.
\end{abstract}

\footnotetext{
${ }^{1}$ Global Security Initiative, Arizona State University, Tempe, USA ${ }^{2}$ School of Sustainability, Arizona State University, Tempe, USA (e-mail: rachata. muneepeerakul@asu.edu) ${ }^{3}$ School of Human Evolution and Social Change, Arizona State University, Tempe, USA (e-mail: jose.lobo@asu.edu) Correspondence: (e-mail: shade.shutters@asu.edu)
} 


\section{Introduction}

espite recent advances in understanding social and economic resilience, economies at all scales are still subject to periodic unforeseen shocks-the recent US/global recession is a case in point. These shocks, or rapid changes in economic activity, can potentially lead to social instability and conflict (for example, Arab Springs). Furthermore, in an era of ever-increasing interconnectedness and globalization, detrimental effects of more localized shocks can be felt far from their origins.

Thus understanding and planning for the aftermath of shocks is critical for minimizing their detrimental effects. Nowhere is this need greater than in the densely populated, highly connected and engineered urban areas of the world. The importance of cities as centres of population and economic activity is now a defining feature of the human species as most of the world's population now resides in cities. The importance of cities will grow as the process of urbanization accelerates in China, India and Africa, and as urban economies worldwide become intricately linked in a global city network.

Given that limited resources may be available to minimize the effects of economic shocks, it is also important to identify which regions are most susceptible to rapid social and economic shifts (Hill et al., 2012; Hallegatte, 2014) or to natural disasters (Cutter et al., 2010). Thus decision makers and researchers alike are increasingly turning to resilience theory as a framework for addressing system shocks. The presence of resilience-themed literature has exploded in the last decade, with peer-reviewed publications in Web of Science increasing over 1,000\% between 2000 and 2010 (Xu and Marinova, 2013). The growing recognition that cities, in particular, must plan for, promote and measure resilience, has led to programmes like the Rockefeller Foundation's recent pledge to fund Chief Resilience Officers in 100 competitively selected cities (see http://www.100resilientcities. org/ for details).

The concept of resilience offers an important framework for assessing the dynamics and trajectories of complex adaptive systems, particularly given the non-linearities typical of such systems (Gunderson and Holling, 2002). A basic premise of resilience theory is that complex systems follow an archetypical adaptive cycle, passing through phases of growth, maturation, collapse and reorganization. This framework has been useful for conceptualizing questions related to complex systems, particularly in coupled human-natural systems. It is frequently invoked as an abstract ideal for framing specific questions or explaining particular phenomena of these systems.

However, formally quantifying the abstract concepts embodied in resilience theory and in its notion of an adaptive cycle has been exceedingly difficult (Walker and Salt, 2012; Tamvakis and Xenidis, 2013). Given the sheer number of interacting system attributes that contribute to resilience, Walker and Salt (2012: 92) assert that it is "difficult, if not impossible, to quantify general resilience". Similarly, in its experience the United States Agency for International Development found it particularly difficult to measure resilience of communities or whole systems (USAID, 2013), and thus turned to quantification of survey data. The lack of quantitative measures of an economy's resilience presents an obstacle to planning responses to shocks. Such a measure would effectively create a comparative index of how severely the effects of shocks will be realized in one area versus another and allow decision makers to prioritize investments and resources to prepare for shocks.

Those attempts that have been made to measure urban resilience typically estimate disaster-related risks of financial and other losses. Even in those cases, resilience measures are primarily of engineered infrastructure such as transportation networks, energy and water delivery systems, or the built environment (for example, Chang and Shinozuka, 2004; Ouyang et al., 2012; Jha et al., 2013; Tamvakis and Xenidis, 2013). Similarly, others have attempted to operationalize urban resilience but these efforts typically resolve to more risk assessment or qualitatively clarifying the contributing factors to resilience (for example, Hill et al., 2008; Wardekker et al., 2010; Sudmeier et al., 2013; Keating et al., 2014; Martin and Sunley, 2015). One notable exception is the Resilience Capacity Index (http://brr.berkeley.edu/rci/), which attempts to measure several dimensions of metropolitan resilience (U.S. Department of Housing and Urban Development, 2012), but which, to our knowledge, has not been empirically validated. Consequently, empirically and quantitatively assessing the resilience of a system more generally remains an obstinate challenge.

Our approach to assessing the resilience of urban systems, or more precisely urban economies, is to quantify an attribute of systems that is intimately related to resilience-system tightness. System tightness can be thought of as the degree of connectedness, integration or interdependence of the components of a system. Exactly how system tightness and system resilience are related is a matter of ongoing debate and a secondary motivation for this study is to contribute to this discussion.

A common assertion is that as a system becomes more tightly connected and integrated, its resilience increases-tightness enhances resilience. In the context of cities, this viewpoint is nicely summarized in a recent study of world megacities (Harris et al., 2014), which asserts that "highly integrated systems .... show high degrees of resilience" (14), and a loosely integrated city like Dhaka "lacks the connectedness .... needed for resilience" (20). This perspective highlighting the positive impacts of higher connectedness comes largely from the engineering concepts of robustness and redundancy (Pavard et al., 2008; Krupa et al., 2014), and are frequently invoked when discussing designed networks or engineered systems (Sterbenz et al., 2014). From this perspective, if one node or set of nodes in a network fails, higher connectivity increases the likelihood that compensating pathways through the network will exist.

On the other hand, the deleterious effects of increasing connectivity among a system's components have been noted in several fields. In complex systems science, increasing connectivity among a system's components is known to hinder the system's search for optimal configurations, illustrated by Kauffman's so-called "complexity catastrophe" (Kauffman, 1993). Likewise, the literature in sociology has demonstrated how increasing systemic complexity can make systems vulnerable to cascading failures (Dorner, 1996). Particularly with regard to networks, it has been shown that when actors embedded in a social network are too densely connected, it can inhibit fruitful collective action (Flache and Macy, 1996, Spector and Klein, 2006). This negative view of connectivity in relation to resilience comes largely from ecology, and is summarized in the so-called Panarchy framework (Gunderson and Holling, 2002). A central tenet of the Panarchy view of resilience is that as systems transition from an exploitation/growth phase to a mature/conservation phase, two things happen: (a) the tightness of the system's connections increases and (b) the resilience of the system decreases. From this perspective, if one node or set of nodes in a network fails, higher connectivity will increase the likelihood that the detrimental effects of that failure will further propagate through the network.

In the discussion section of this paper we propose a reconciliation of these seemingly opposing views regarding the relationship between tightness and resilience. Yet under either perspective, it follows that by measuring where a city's economy lies along a transitional continuum-in terms of tightness-we 
also determine where it lies in terms of resilience. Therefore, this study undertakes the challenge of quantifying resilience by first developing a quantitative measure of system tightness or connectedness for the social-economic systems we call cities. Using data on US urban employment, we develop a metric to quantify the interdependence of labour occupations that exist in US urban economies, allowing comparisons of how tightly interconnected each urban economy is.

To assess the validity of this novel metric of resilience, we compare a city's tightness to various measures of economic performance during the recent (2007-2009) recession. Specifically, we compare our tightness metric, as calculated for 2006 versus the changes in a suite of economic performance measures from 2006 to 2009 and again from 2006 to 2012. In addition, we highlight the positive aspects of higher tightness by determining its effect on a number of economic performance indicators in the absence of an economic shock.

\section{Methods}

Our units of analysis are the nearly 400 Metropolitan Statistical Areas (MSAs) of the United States. Metropolitan Areas encompass geographical areas of economic cohesion as opposed to actual city political boundaries. To calculate our metric we use publicly available data on urban employment compiled by the US Bureau of Labor Statistics (BLS) in its Occupational Employment Survey (BLS, 2014). The datasets that were analysed have been made publicly available in the Dataverse repository (Shutters S, Muneepeerakul R, Lobo J, 2015). These data capture the numbers of workers employed in approximately 800 different occupations in each MSA and, consequently, the skill sets prevalent in the labour pool of an MSA's economy at a given point in time (Jones and Romer, 2010; Glaeser, 2011; Florida, 2012; Gabe et al., 2012). We focus on city-level occupational data in the United States due to their availability and the inherent importance of urban economies to both the U.S. and global economies. MSAs account for nearly $85 \%$ of U.S. population and over $90 \%$ of U.S. economic output.

Our method starts by determining an urban economy's set of occupational specializations. An MSA is considered to be specialized in an occupation if the fraction of the city's employment in that occupation is greater than the fraction nationally. The ratio of these two fractions is equivalent to the traditional economic metric of location quotient. The location quotient of occupation $i$ in MSA $m$ is defined as

$L Q_{i}^{(m)}=\frac{\left(x_{i}^{(m)} / \sum_{i} x_{i}^{(m)}\right)}{\left(\sum_{m} x_{i}^{(m)} / \sum_{m} \sum_{i} x_{i}^{(m)}\right)}$

where $x_{i}^{(m)}$ is the number of workers employed in occupation $i$ in MSA $m$. Thus, a city's specialty occupations are those that have a location quotient $L Q_{i}^{(m)}>1$. The resulting set of specialty occupations for each city provides a unique signature indicative of a city's prevalent skill sets and its comparative labour advantage.

Using conditional probabilities, we then define the interdependence between any pair of occupations $i$ and $j, \zeta_{i j}$, as

$\zeta_{i j}=\frac{P\left[L Q_{i}^{(m)}>1, L Q_{j}^{(m)}>1\right]}{P\left[L Q_{i}^{\left(m^{\prime}\right)}>1\right] P\left[L Q_{j}^{\left(m^{\prime \prime}\right)}>1\right]}-1$

where $m, m^{\prime}$ and $m^{\prime \prime}$ denote a randomly selected MSA (Muneepeerakul $e t$ al., 2013). Thus we generate a matrix of interdependencies which is calculated for every pair of the approximately 800 occupations tracked by the BLS and which is independent of any particular city. A positive $\zeta_{i j}$ indicates that specializations in the two occupations, $i$ and $j$, co-occur more often than would be expected if they were independent, implying that the two occupations may share some common requirements or may contribute to shared economic outputs. The opposite is true for negative $\zeta^{\prime}$ s, in which case the occupations may be in competition for similar labour skills or may otherwise hinder each other's presence.

Essentially, our metric is an information-based metric, which is an increasingly preferred approach to quantifying resilience, sustainability and similar attributes of complex adaptive social systems (Ulanowicz et al., 2009; Bossomaier et al., 2013, Tamvakis and Xenidis, 2013; Mayer et al., 2014). Thus our initial inspiration for this metric was based on Hidalgo et al.'s (2007) measure of national production interdependencies. However, like traditional information-based metrics of distance, Hidalgo's measure was restricted to positive values, while $\zeta$ additionally recognizes negative interdependencies.

Note that $\zeta$ measures the interdependence between any two occupations (Muneepeerakul et al., 2013). To define a single metric of resilience that may be compared across cities, we use $\zeta$ to develop an aggregate metric of a city's magnitude of economic interconnectedness or tightness. We first calculate a weighted and normalized interdependence value for the link between each pair of a city's specialty occupations:

$L_{i, j}^{(m)}=\frac{\left(e_{i}^{(m)}+e_{j}^{(m)}\right) \zeta_{i j}}{2 \sum_{k=1}^{n^{(m)}} e_{k}^{(m)}}$

where $m$ is a given MSA, $n^{(m)}$ is the number of occupations in city $m$ which have employees (active occupations) and $e_{i}^{(m)}$ is the number of workers employed in occupation $i$ in city $m$. Thus, a link's interdependence value $L$ is weighted by the mean number of employees of the two occupations connected by the link and is normalized by the city's total employment.

For each city, this weighted interdependence $L$ is then averaged across all links in the city's specialty portfolio to derive an aggregate measure of "tightness" $T$ of the city's economy:

$T^{(m)}=\frac{2}{\boldsymbol{s}^{(m)}\left(\boldsymbol{s}^{(m)}-1\right)} \sum_{i<j}^{s^{(m)}} L_{i, j}^{(m)}$

where $s^{(m)}$ is the number of occupations in city $m$ 's set of specialty occupations. Qualitatively stated, if a city's value of $T$ is high, its economy is more tightly connected and positively interdependent than in cities with a low value of $T$. While others have attempted to measure the regional effects of interdependent and clustered industries (for example, Delgado et al., 2014), our measure is instead derived from data on labour occupations.

\section{Results and discussion}

Figure 1 shows that, across cities at a given point in time, as tightness increases so does economic performance (Table 1). This demonstrates the positive relationship between tightness and economic performance when effects of shocks are not considered. This is not unexpected as resilience theory, within the Panarchy framework, asserts that increasing tightness is associated with higher capital and efficiency.

However, in response to a shock, our expectation was that cities with a lower $T$ would consequently have higher resilience and would therefore fare better in the recent recession. This is indeed supported by our results. Figure 2 compares our measure $T$ to changes in three economic performance measures from 2006 to 2009 (see Table 1 for full list of indicators and regressions). These time points were chosen to correspond to points before the recession and at the end of the recession respectively. For all measures of economic performance, simple correlation between $T$ and changes due to the recession were negative. Thus, in urban economies with larger $T$ the effects of the recent recession were, on average, more severe 3 years after the start of the recession.

Table 1 compares these correlations to the same measures 6 years after the start of the recession. In all cases, the change in economic performance from 2006 to 2012 is still negatively correlated with tightness, but the magnitude has decreased in all cases compared to 3 years earlier (Table 1). This suggests that economies with higher tightness are slowly rebounding from the economic shock but are still in what Ouyang and Dueñas-Osorio (2012) refer to as the recovery phase.

Taken together these results highlight the tradeoff that exists with regard to resilience and economic performance. For every indicator other than employment, the correlation between tightness and economic performance was positive, while the correlation between tightness and response to economic shock was negative.

Using $T$ we also speculate on the impact of the recent recession on the aggregate US economy. Because cities in the United States account for over $90 \%$ of the country's economic output, aggregating across the 364 cities of this study should approximate phenomena at the national level. Figure 3 shows the mean value of $T$ across all 364 metropolitan areas for each year 2006-2013. According to the U.S. National Bureau of Economic Research (2012), the recent recession officially began in late 2007 and ended in mid-2009. Thus Figure 3 suggests that as the recession came into full effect, the nation underwent a general "loosening" of its economy. But what exactly does this mean? 

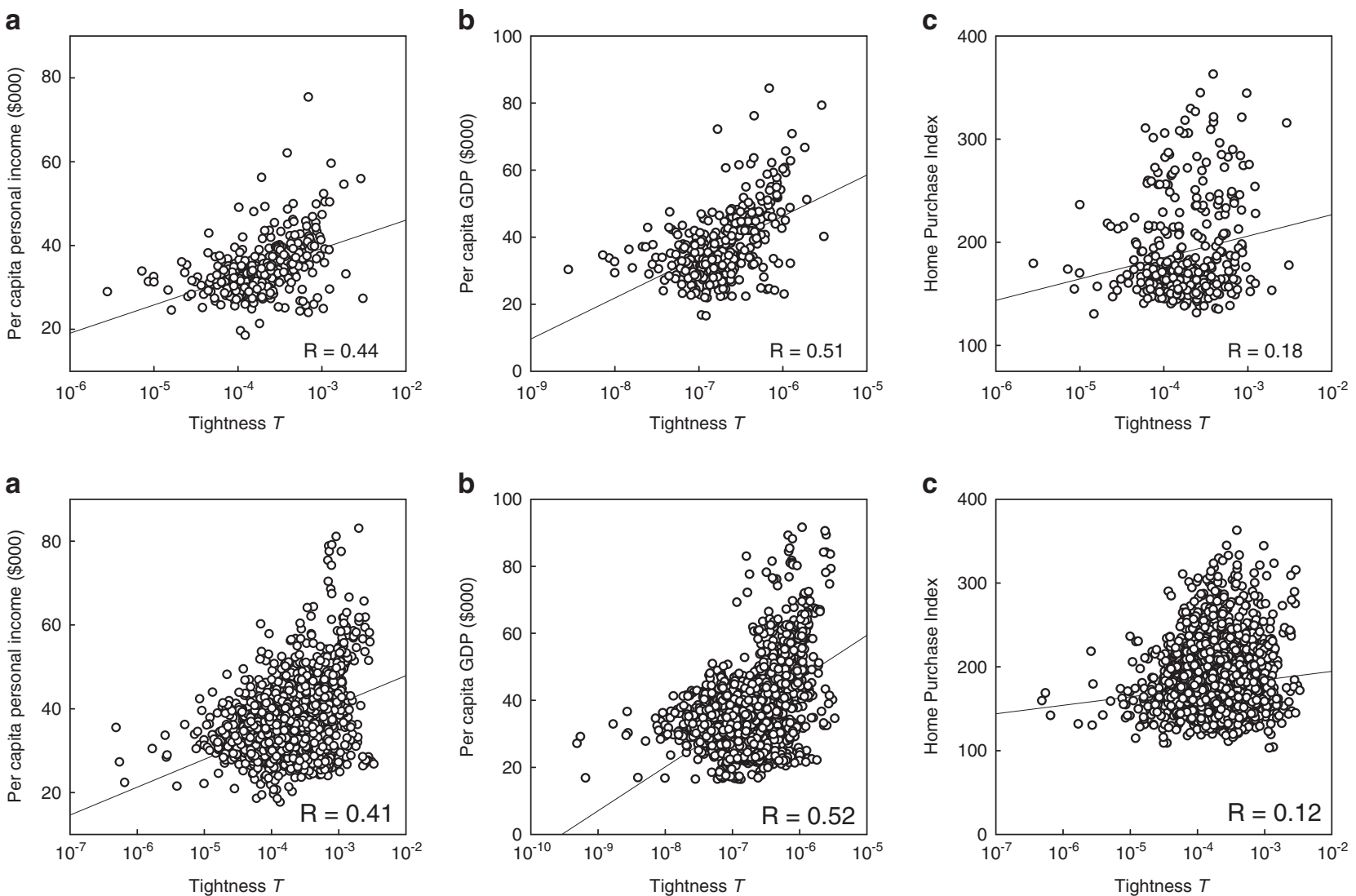

Figure 1 | Economic performance versus tightness T. Each graph illustrates how 364 US Metropolitan Statistical Areas (MSAs) performed in a given year vs. the MSA's tightness value for that year. The top three figures show results for $\mathbf{2 0 0 6}$ only while the bottom three include data for the years 2005-2013. Each point represents a single MSA whose value of $T$ is plotted against (a) nominal per capita personal income, (b) real per capita GDP and (c) home purchase index. The $x$-axis is logarithmic in each case.

Table 1 | Data, their sources and simple correlation coefficients for $T$ versus both non-shock measures and changes in measures of urban performance following the recent economic recession

\begin{tabular}{|c|c|c|c|c|c|}
\hline \multirow[b]{2}{*}{ MSA-level data $(N=364)$} & \multirow[b]{2}{*}{ Source ${ }^{\#}$} & \multirow[b]{2}{*}{$\begin{array}{l}\text { Years } \\
\text { covered }\end{array}$} & \multicolumn{3}{|c|}{ Simple correlation coefficient. of $T$ versus: } \\
\hline & & & $\begin{array}{l}\text { Change }^{\star} \text { in } \\
\text { performance } \\
\text { after } 3 \text { years }\end{array}$ & $\begin{array}{l}\text { Change }^{\star} \text { in } \\
\text { performance } \\
\text { after } 6 \text { years }\end{array}$ & $\begin{array}{c}\text { Non-shock } \\
\text { performance }\end{array}$ \\
\hline \multicolumn{6}{|l|}{ Labour data } \\
\hline Occupational counts & BLS & 2005-2013 & - & - & - \\
\hline \multicolumn{6}{|l|}{ Measures of economic performance } \\
\hline Per capita nominal personal income & BEA & $2005-2012$ & -0.35 & -0.21 & 0.41 \\
\hline Per capita real GDP & BEA & $2005-2012$ & -0.11 & -0.05 & 0.56 \\
\hline Annualized home purchase index & FHFA & $2005-2013$ & -0.20 & -0.18 & 0.15 \\
\hline Employment rate & BLS & $2005-2013$ & -0.17 & -0.11 & -0.04 \\
\hline Per capita real personal income & BEA & $2008-2012$ & - & - & 0.30 \\
\hline Annual real wages per job & BEA & $2008-2012$ & - & - & 0.56 \\
\hline \multicolumn{6}{|l|}{ Other demographic measures } \\
\hline Population & $\mathrm{CB} 1$ & $2005-2013$ & 0.12 & - & 0.39 \\
\hline Weighted population density & CB2 & 2010 & - & - & 0.44 \\
\hline
\end{tabular}

\#Explanation of data sources:

BLS-US Bureau of Labor Statistics (BLS, 2014).

BEA-US Bureau of Economic Analysis (BEA, 2014).

FHFA-US Federal Housing Finance Agency (FHFA, 2014).

CB1-US Census Bureau (U.S. Census Bureau, 2014b).

CB2-US Census Bureau (U.S. Census Bureau, 2014a)

${ }^{\star}$ Calculated only for variables that had both 2006 and 2009 data.

The datasets that were analysed from the above sources are available in the Dataverse repository (Shutters S, Muneepeerakul R, Lobo J, 2015). 

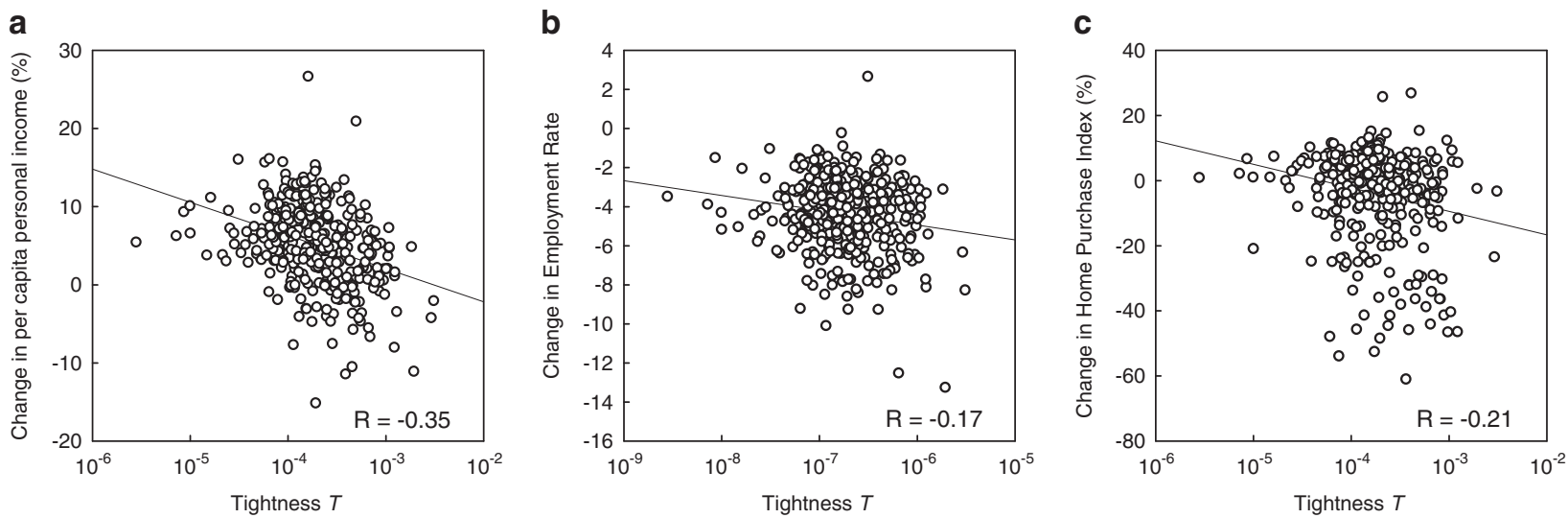

Figure 2 | Change in economic performance due to the recent recession versus tightness T. Each graph illustrates how 364 US Metropolitan Statistical Areas (MSAs) fared during the recent recession versus our metric of the city's tightness. Each point represents a single MSA whose 2006 value of $T$ is plotted against (a) percent change in nominal per capita personal income 2006-2009, (b) change in employment rate 2006-2009 and (c) percent change in home purchase index 2006-2009. The $x$-axis is logarithmic in each case.

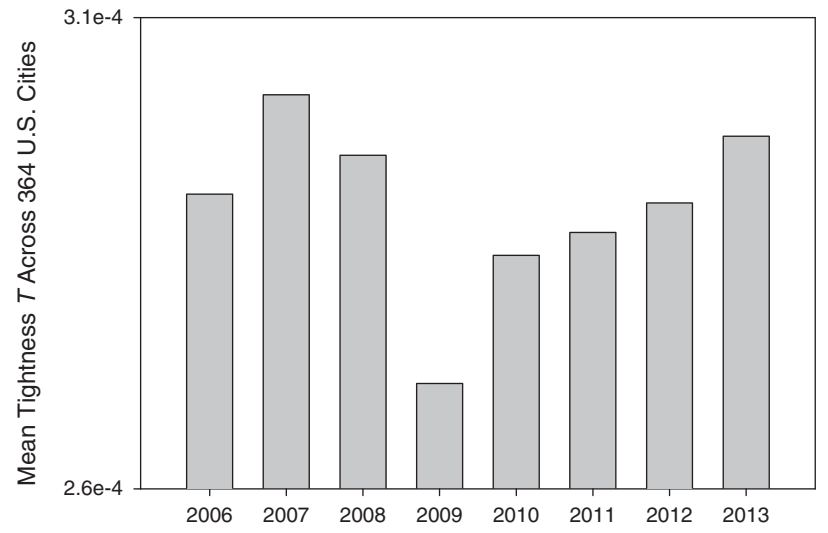

Figure 3 | Average tightness T of US cities, 2006-2013. For each year the mean value of $T$ for all 364 cities used in this study is shown.

The Panarchy framework of resilience predicts that as systems at one hierarchical level experience a shock, lower level systems are subject to collapse, during which their tightness and bound resources are released (Gunderson and Holling, 2002). These lower level systems might be neighbourhoods, firms, school districts, households, individuals or numerous other entities that make up an urban economy. In terms of resilience's adaptive cycle, these lower level systems have entered the " $K$ to $\Omega$ phase", a time during which "potential plummets" (Gunderson and Holling, 2002: 45). Perhaps this release of resources is reflected in the US Federal Reserve's estimate that US households shed over US $\$ 16$ trillion in net worth during the recession-nearly $25 \%$ of the nation's accumulated wealth (Atkinson et al., 2013).

The cumulative effect of these collapses and releases coincides with a drop in mean $T$ from 2007 to 2008 (Fig. 3), the first year following the start of the recession. In effect, urban economies began to shed some of their tightness as well as resources. From 2008 to 2009, mean national tightness fell even further. After that point the recession officially ended and mean national tightness has increased every year since.

Interestingly, Figure 3 shows that US cities quickly reconfigured labour resources into the tightly interdependent arrangements associated with superior economic performance (Fig. 2). Thus, in one sense, cities rapidly trade economic resilience or robustness for higher economic efficiency, despite having very recently experienced the detrimental effects of an economic shock. While some have argued that this is indicative of a superior crisis response by the United States (Hilsenrath, 2014), one might also argue that Figure 3 represents an example of collective short-term memory and that US cities are simply positioning themselves for a similar response to the next generalized economic shock.

\section{Is tightness good or bad for resilience?}

Our empirical evidence supports the Panarchy perspective that, in the context of urban economies, increasing tightness of connections decreases resilience. However, this should in no way be interpreted as rejecting the counterview that increasing connectedness enhances resilience. Indeed it is likely that the role of tightness, connectedness, integration or interdependence is more complicated than merely an ecological versus engineering dichotomy.

We propose that the relationship between tightness and resilience is moderated by the scale of a shock or disruption. Viewing the components of a system as nodes in a network, a shock may affect part of the system-one or a small subset of nodes-or it may be system-wide-affecting virtually all nodes. It is plausible that, from the perspective a single node in this network, a system-wide shock will favour lower connectedness to the rest of the disrupted system, so that the node in question is in some sense insulated from the effects of a generalized shock. This relates to the ecological concept of fragility of highly interconnected ecosystems arising from interdependence. On the other hand, from the perspective of that same single node, if the node is affected by a localized shock, having increased connectivity to unaffected parts of the system permits a more rapid influx of resources to stabilize the node and alleviate effects of the shock. This relates to the engineering concepts of system robustness or resilience arising from redundancy.

Anecdotal evidence from this study supports this proposition. The recent recession is an example of a system-wide shock (both to the US and global economies) during which individual urban economies (nodes) were less affected economically when they had lower economic tightness. Thus, further elucidating the circumstances under which system resilience is hindered or enhanced by the system's degree of connectivity, presents a tantalizing direction for future research.

\section{Conclusions}

Our primary goal in this study was to develop an objective and quantitative metric of resilience by quantifying tightness of a 
system, and to test that metric using empirical data. We assessed the validity of our metric as a predictor of response to shocks using data representative of economic shocks. Given that our metric may help anticipate which cities will perform better or worse following an economic shock, it should be further validated by assessing cities' responses to other types of shocks. In particular, resilience to natural disasters and other environmental pulse events might be tested. In addition, data that quantifies shocks to a city's socio-political fabric, such as sudden policy changes, social upheaval (for example, unrest following the recent police shooting in Ferguson, Missouri), or rapid cultural shifts, should be used to test the predictive capabilities of our metric.

Once the utility of our method is further validated, it can be applied to other countries, provided that comprehensive, high-quality data sets are available at the required scale. By comparing the application of this method to different countries and at different scales we will have a more complete picture of how economic interconnectedness and societal resilience play out in different contexts and at different stages of economic development.

Although not explicitly stated above, what we actually create through our metric is a weighted network representing the intricate web of interdependencies between labour occupations. In this network, the nodes are individual occupations and the weights between links are the interdependencies between occupations. Thus our method makes quantifying resilience amenable to the considerable tool set of network analysis and our study is just a first step in exploring the vast possibilities that network science may have to offer.

More generally, we have assessed the tightness of a complex system by quantifying the tightness of the network that structures the internal workings of that system. Thus our method may be applicable to almost any complex adaptive system, as networks are ubiquitous components of such systems.

\section{References}

Atkinson T, Luttrell D and Rosenblum H (2013) How bad was it? The costs and consequences of the 2007-09 financial crisis. Staff Papers-Federal Reserve Bank of Dallas; 20 (July): 1-22.

BEA. (2014) Regional Economic Accounts. Bureau of Economic Analysis, U.S. Department of Commerce, http://www.bea.gov/regional/index.htm, accessed 7 January 2014.

BLS. (2014) Occupational Employment Survey. Bureau of Labor Statistics, U.S. Department of Labor, http://www.bls.gov/oes/, accessed 24 July 2014

Bossomaier T, Barnett L and Harré M (2013) Information and phase transitions in socio-economic systems. Complex Adaptive Systems Modeling; 1: 9.

Chang S E and Shinozuka M (2004) Measuring Improvements in the disaster resilience of communities. Earthquake Spectra; 20 (3): 739-755.

Cutter S L, Burton C G and Emrich C T (2010) Disaster resilience indicators for benchmarking baseline conditions. Journal of Homeland Security and Emergency Management; 7 (1): 51.

Delgado M, Porter M E and Stern S (2014) Clusters, convergence, and economic performance. Research Policy; 43 (10): 1785-1799.

Dorner D (1996) The Logic of Failure: Recognizing and Avoiding Error in Complex Situations. Metropolitan Books: New York.

FHFA. (2014) House Price Index Datasets. U.S. Federal Housing Finance Agency, http://www.fhfa.gov/DataTools/Downloads/Pages/House-Price-Index-Datasets. aspx, accessed 28 February 2014

Flache A and Macy M W (1996) The weakness of strong ties: Collective action failure in a highly cohesive group. Journal of Mathematical Sociology; 21 (1-2): $3-28$.

Florida R (2012) The Rise of the Creative Class-Revisited: 10th Anniversary EditionRevised and Expanded. Basic Books: New York.

Gabe T, Abel J, Ross A and Stolarick K (2012) Knowledge in cities. Urban Studies; 49 (6): $1179-1200$.

Glaeser E L (2011) Triumph of the City: How Our Greatest Invention makes us Richer, Smarter, Greener, Healthier and Happier. Penguin Press: London.

Gunderson L H and Holling C S (eds) (2002) Panarchy: Understanding Transformations in Human and Natural Systems. Island Press: Washington DC.
Hallegatte S (2014) Economic Resilience: Definition and Measurement, Policy Research Working Paper, no. WPS 6852. The World Bank, Climate Change Group: Washington DC.

Harris M, Dixon R, Melin N, Hendrex D, Russo R and Baily M (2014) Megacities and the United States Army: Preparing for a Complex and Uncertain Future. Chief of Staff of the Army, Strategic Studies Group: Arlington, VA.

Hidalgo C A, Klinger B, Barabasi A L and Hausmann R (2007) The product space conditions the development of nations. Science; 317 (5837): 482-487.

Hill E et al (2012) Economic shocks and regional economic resilience. In: Pindus N, Weir M, Wial H, Woman H (eds) Building Resilient Regions: Urban and Regional Policy and Its Effects. Brookings Institution Press: Washington DC, pp 193-274.

Hill E W, Wial H and Wolman H (2008) Exploring Regional Economic Resilience (Working Paper 2008-04). University of California, Institute of Urban and Regional Development.

Hilsenrath J (2014) What Big Economies Got Right, or Wrong, After Crisis: Why the U.S. and U.K. Have Fared Better Than Japan and Europe. The Wall Street Journal, Eastern Edition 24 November.

Jha A K, Miner T W and Stanton-Geddes Z (eds) (2013) Building Urban Resilience: Principles, Tools, and Practice. World Bank Publications: Washington DC.

Jones C I and Romer P M (2010) The new kaldor facts: Ideas, institutions, population, and human capital. American Economic Journal-Macroeconomics; 2 (1): 224-245.

Kauffman S A (1993) The Origins of Order: Self-Organization and Selection in Evolution. Oxford University Press: New York.

Keating A et al (2014) Operationalizing Resilience against Natural Disaster Risk Opportunities, Barriers, and a Way Forward. Zurich Flood Resilience Alliance, http://opim.wharton.upenn.edu/risk/library/zurichfloodresiliencealliance_ ResilienceWhitePaper_2014.pdf.

Krupa M B, III F S C and Lovecraft A L (2014) Robustness or resilience? Managing the intersection of ecology and engineering in an urban Alaskan fishery. Ecology and Society; 19 (2): 17.

Martin R and Sunley P (2015) On the notion of regional economic resilience: Conceptualization and explanation. Journal of Economic Geography; 15 (1): 1-42.

Mayer A L, Donovan R P and Pawlowski C W (2014) Information and entropy theory for the sustainability of coupled human and natural systems. Ecology and Society; 19 (3): 11.

Muneepeerakul R, Lobo J, Shutters S T, Goméz-Liévano A and Qubbaj M R (2013) Urban economies and occupation space: Can they get "there" from "here"? Plos One; 8 (9): e73676.

National Bureau of Economic Research. (2012). US business cycle expansions and contractions, http://www.nber.org/cycles.html, accessed 2 September 2014.

Ouyang M and Dueñas-Osorio L (2012) Time-dependent resilience assessment and improvement of urban infrastructure systems. Chaos; 22 (3): 0333122

Ouyang M, Dueñas-Osorio L and Min X (2012) A three-stage resilience analysis framework for urban infrastructure systems. Structural Safety; 36-37 (May-July): 23-31.

Pavard B, Dugdale J, Saoud N B-B, Darcy S and Salembier P (2008) Underlying concepts in robustness and resilience and their use in designing socio-technical systems. In: Hollnagel E, Nemeth C P, Dekker S (eds) Resilience Engineering Perspectives: Remaining Sensitive to the Possibility of Failure. Ashgate Publishing: Burlington, VT, pp 127-142.

Shutters S, Muneepeerakul R and Lobo J (2015) Replication Data for: Quantifying urban economic resilience through labour force interdependence. Dataverse. http://dx.doi.org/10.7910/DVN/HEWGDD

Spector L and Klein J (2006) Genetic stability and territorial structure facilitate the evolution of tag-mediated altruism. Artificial Life; 12 (4): 553-560.

Sterbenz J G et al (2014) Redundancy, diversity, and connectivity to achieve multilevel network resilience, survivability, and disruption tolerance invited paper. Telecommunication Systems; 56 (1): 17-31.

Sudmeier K I, Jaboyedoff M and Jaquet S (2013) Operationalizing "resilience" for disaster risk reduction in mountainous Nepal. Disaster Prevention and Management: An International Journal; 22 (4): 366-377.

Tamvakis P and Xenidis Y (2013) Comparative evaluation of resilience quantification methods for infrastructure systems. Procedia-Social and Behavioral Sciences; 74 (2013): 339-348.

U.S. Census Bureau. (2014a) Metropolitan and Micropolitan Population Density Profiles. United States Census Burean, U.S. Department of Commerce, http:// www.census.gov/population/metro/data/pop_pro.html, accessed 24 January 2014.

U.S. Census Bureau. (2014b) Population Estimates. United States Census Bureau, U.S. Department of Commerce, http://www.census.gov/popest/data/index.html, accessed 12 January 2014.

U.S. Department of Housing and Urban Development. (2012) Conceptualizing and measuring resilience. Evidence Matters, Winter 2012: article 2, http://www .huduser.org/portal/periodicals/em/winter12/highlight2.html.

Ulanowicz R E, Goerner S J, Lietaer B and Gomez R (2009) Quantifying sustainability: Resilience, efficiency and the return of information theory. Ecological Complexity; 6 (1): 27-36. 
USAID. (2013) The Resilience Agenda: Measureing Resilience in USAID, Technical Note 1866. United States Agency for International Development: Washington DC.

Walker B and Salt D (2012) Resilience Practice: Building Capacity to Absorb Disturbance and Maintain Function. Island Press: Washington DC.

Wardekker J A, de Jong A, Knoop J M and van der Sluijs J P (2010) Operationalising a resilience approach to adapting an urban delta to uncertain climate changes. Technological Forecasting and Social Change; 77 (6): 987-998.

Xu L and Marinova D (2013) Resilience thinking: A bibliometric analysis of socioecological research. Scientometrics; 96 (3): 911-927.

\section{Data Availability}

The datasets analysed during the current study are available in the Dataverse repository: http://dx.doi.org/10.7910/DVN/HEWGDD. These datasets were derived from the following public domain resources:

http://www.bea.gov/regional/index.htm; http://www.bls.gov/oes/; http://www.fhfa.gov/ DataTools/Downloads/Pages/House-Price-Index-Datasets.aspx; http://www.census .gov/population/metro/data/pop_pro.html; http://www.census.gov/popest/data/index .html

\section{Acknowledgements}

For valuable feedback on this work we thank David Shanafelt, the faculty of the Center for Urban Resilience at Loyola Marymount, and two anonymous reviewers.

\section{Additional Information}

Competing interests: The authors declares no competing financial interests.

Reprints and permission information is available at http://www.palgrave-journals.com/ pal/authors/rights_and_permissions.html

How to cite this article: Shutters ST, Muneepeerakul R and Lobo J (2015) Quantifying urban economic resilience through labour force interdependence. Palgrave Communications 1:15010 doi: 10.1057/palcomms.2015.10.

(c) (i) This work is licensed under a Creative Commons Attribution 3.0 BY International License. The images or other third party material in this article are included in the article's Creative Commons license, unless indicated otherwise in the credit line; if the material is not included under the Creative Commons license, users will need to obtain permission from the license holder to reproduce the material. To view a copy of this license, visit http://creativecommons.org/licenses/by/3.0/ 